September - 2006

\title{
Distance Learning Program of Teachers' at Kigali Institute of Education: An expository study
}

\author{
Dariya Mukamusoni \\ Kigali Health Institute \\ Rwanda
}

\begin{abstract}
In 2001, a program of distance learning was started within Kigali Institute of Education in collaboration with the Rwanda's Ministry of Education. It is an in-service training program that aims to upgrade in-service secondary school teachers and alleviate the shortage of teachers both in terms of quality and number. This program runs parallel to a pre-service program, also conducted within the Kigali Institute. Academic staff members working in the pre-service program are involved in this distance learning program. After three years, a descriptive qualitative case study was conducted to determine the experiences of academic staff involved in the distance learning program. Purposive and theoretical sampling was used for participants' identification and inclusion. Individual unstructured interview and focus group discussion was used to gather the data. A qualitative software analysis called NVivo 2, developed by Qualitative Solutions and Research (QSR) International in 2002, was used to compile and analyse the data. Results of the study revealed that faculty members involved in both in-service and pre-service programs face challenges associated with heavy workload. Moreover, the pre-service program is typically prioritized at the expense of the distance learning in-service program. Academic relationships between faculty members and tutors also need to be reinforced. Serving as the critical link between the distance learning in-service program and pre-service departments and faculties, this research also shows that course coordinators play a pivotal role in the smooth operation of the distance learning program.
\end{abstract}

Keywords: distance learning; distance learning program; academic staff of distance learning

\section{Background}

After the 1994 genocide in Rwanda, the country faced critical shortages of human resources both in terms of quality and quantity. The education system was particularly affected by the genocide, a situation which led to the establishment of higher learning institutions by the Government of Rwanda. Sufficient numbers of qualified teachers are the cornerstone of the Millennium Development Goals to which the Government of Rwanda is committed. It is within this political context that Kigali Institute of Education was formed.

Kigali Institute of Education was established in January 1999 by the Government of Rwanda to help address the shortage of qualified teaching staff at the secondary level and the shortage of managerial staff needed to run technical and vocational training institutions. Up to 65 percent of secondary teachers in Rwanda were found to be under-qualified in 1999 (Rwanda Ministry of Education, 1999). The mission of the Institute is to undertake training in research, curriculum development, and innovation and improvement of instructional methods. The Kigali Institute of 
Education - which comprises three faculties: Faculty of Science, Faculty of Arts and Social Sciences, and Faculty of Education - aims to be the centre of excellence in educational training and staff development in Rwanda.

Although Kigali Institute of Education started by offering an on-campus program, in order to fulfill its mission of providing Rwanda with qualified teachers, the Institute determined it needed to establish a distance learning (DL) program as a compliment to its existing on-campus learning and teaching model. Distance learning became an alternative for two reasons. First, because there are many under qualified in-service teachers working on the ground, and second, there are no qualified teachers to replace them should they leave for training and upgrading. Distance education, therefore, was chosen as a viable mode of training delivery for this targeted group of educators.

In 2000, the Kigali Institute launched its distance training mode for teachers; it currently serves 500 individuals currently teaching in registered secondary schools in Rwanda. Ten study centers were opened as outlets for this program. After successful completion of the three year program, fully trained teachers will be awarded a Diploma in Education. This diploma will enable them to further their study should they wish to earn a Bachelor of Education.

Distance education is truly an innovation in the Rwandan education system. Because distance education is viewed as a viable innovation, one of the objectives of the Rwandan Government has been to develop the required human resources to run the DL system as soon as possible. Implementing DL programs within such a compressed timeframe, however, does pose considerable challenges.

This study sheds light and insight into the ongoing challenges associated in implementing these DL programs. Results from this study aim to provide informed research upon which to make decisions to improve the overall success of the DL program. The scope of this study is to assess, evaluate, and analyse the process of implementation of DL mode of learning as it relates to inservice teachers, with particular focus paid to the involvement of the academic staff towards its realisation.

Although numerous reasons have been advanced for the adoption of DL within the traditional mode, progress to date has been limited because few educators have to yet gain sufficient understanding of DL to create a viable implementation plan for developing distance education methods (Garrison, 2000). The challenge here, therefore, is not to decide why tertiary education institutions should have distance education, but instead to decide how to design and implement such a program. Specifically, we must gain understanding in 'how to plan' and 'implement a successful program’ (Levy, 2003).

Some studies have exposed various challenges that face the implementation of distance education programs, especially with regards to the academic staff involved (Clarke, Butler, Schmidt-Hassen and Somerville 2004; Williams, 2003). A Delphi study by Rockwell, Furgason and Marx (2000) focused on the planning that occurs as distance education develops, structuring decisions required for distance education, the implementation process, and evaluation needs in documenting outcomes. The study aimed at identifying research and evaluation priorities for distance education. The study reported the main concerns of the most experienced educators involved in the distance education, who were the members of the Delphi panel. Faculty time, competencies, and incentives to develop and teach at distance were also cited as major challenges (among others) in the implementation of distance education. As far as faculty were concerned, however, there was a disconnect between the time needed to prepare and deliver distance education courses and the time needed for research (Rockwell, Furgason and Marx, 1999). Williams (2003) identified barriers to distance education both inside and outside the higher education community. 
According to Williams, inside the academy, distance education programs encounter numerous obstacles and challenges such as the academy's acceptance of distance education as an appropriate teaching method, stiff competition for limited financial resources, and the ability to withstand slow governance procedures. Moreover, as Anderson and Middleton (2002) report, faculty members typically do not want to change their style of instruction and feel that interactive lectures, small group activities, or closed laboratories are the only way that a subject can be taught.

\section{Methodology}

The study is a qualitative descriptive case study. The case study methodology as described by Yin (2003) guided the design of this study. Purposive and theoretical sampling was used to identify and include academic staff involved in the DL implementation process. Thus, only those that were most informed were identified to participate in this study. The information saturation determined the sample size. Nine respondents (two from the top management, three faculty members, two course coordinators, and two from the distance learning office) were individually interviewed. Two focus group discussions were conducted. One focus group was composed of four tutors; the second focus group was composed of seven staff from study centres and students' support office. An interview guide designed by the researcher was used both for interview and focus group discussion. The interview guide focused on the recruitment procedure, distance learning skills, staff workload, and working relationship issues. All interviews and focus group discussions were recorded on audiotapes and later transcribed. The data were compiled and subjected to qualitative analysis software called NVivo 2, developed by Qualitative Solutions and Research (QSR) International in 2002. This software was used to analyse the data by identifying the emerging themes and patterns. After the themes and patterns identified, the software helped to link the information provided from different interviewees to the identified themes and patterns.

\section{Results}

There were three categories of academic staff involved in the process of DL implementation: 1.) academic staff from faculties who maintain their departmental status as well; 2.) course coordinators hired as full time staff of the DL program; and 3.) tutors located in different study centres through out Rwanda. Academic staff members write the module and make sure the written courses contain the same course contents as is taught in the on-campus program. The course coordinators act as liaisons between the distance learning program and the departments; they plan the modules, write the modules, proof read the modules, and generally make sure they are ready on time. Finally, the course tutors work in the field with distant education students to facilitate learning during the course of the program.

\section{Staff recruitment for distance learning program}

The management policy on recruitment mandates that it is the Institute's academic lecturer who is responsible for developing the DL course materials, follow-up with individual distant learners, while at the same time oversee the pre-service program activities in both the academic and administration aspects. Thus, it was stipulated in lecturers' contracts that they cater to both programs, pre-service and in-service. As one academic lecturer said:

DL program activities are part of our duties. I should recognize that it is in my contract of appointment. But it is not easy to combine both module writing and the pre-service work. 
The course tutors were selected among the few qualified teachers on the ground and were requested by the Ministry of Education to facilitate the DL program. Two course tutors reported their appointment as follows:

To join the [DL] program we did not apply, but we were just selected and contacted that we are qualified teachers in our subjects and we will be doing tutorials for the distance training program of teachers.

Course coordinators, in addition to other staff at the distance learning program office and study centers, were recruited specifically for the work they were doing.

\section{Capacity building in distance learning competencies}

When they first joined the program, most staff members did not have any previous experience in distance education. They therefore had to undergo training in almost all aspects of distance education, a point that is articulated in the following two extracts:

When we started this program, we were not distance education specialists but then we got a lot of assistance from outside specialists. So we have undergone a lot of training and supervision. Nobody in the Kigali Institute of Education from the top management to our level had an idea about distance learning in terms of teaching.

Like most of the other staff in this program, when we started we needed help as we did not have any background in distance training. But the director who knew our shortcoming organized training for us.

This shortcoming was addressed through intensive and ongoing capacity building and staff development, which has since become a cornerstone of this program. As one participant noted:

This program is new for everybody here and in the Country, we have been benefiting from training from external experts who used to come and train us on the issue of distance education and students support system. We have a link with the University of London, which has a long experience in distance learning. And they will come to train us and share with us their experience. We would discuss with them the problem we are facing and they will advise us. We started from zero and we have worked some time through try and error, but now we have very much improved.

\section{Workload and incentive for faculty members}

The data revealed several interesting findings. Although the recruitment policy did help to get faculty members involved in the DL program, it was not enough to meet their needs, nor was it applied to all requisite faculties. Indeed, most faculty members complained of being overworked and overloaded and as a result, they asked for compensation for writing DL course modules. Remuneration against a written module and recognition of the module as an academic work were considered. This finding is articulated in the following excerpt:

To come back to the challenge of faculties, at the beginning they were writing the module for free as part of their work. Then they keep complaining and the head of the program got some money for them [and] now they are paid. They get the 
money when they produce the module, which is a bit encouraging and motivates them.

It was revealed in the data, however, that monetary reward is not the only thing that motivates faculty members. Indeed, the intrinsic motivation that really energised faculty is clearly articulated in the following statement:

We are learning new things, although it is demanding, and we do appreciate especially the exchange we have with the University of London from which we have learned a lot.

\section{Lecturer/course writers and course coordinators: Different priorities}

Materials development emerged as one of the major tasks in the process of the Kigali Institute's DL program. The data showed that materials development is an activity that involves careful planning, coordination, team work, and capacity and expertise in the field of distance education on the part of the course coordinators as well as faculty members. It also revealed the interplay and tension between the tasks that need to be done (module development and production), the structure in which those tasks are accomplished (planning, coordination, team work), technology used (module features, deadlines), and different people carrying out the tasks (expertise, workload). In the larger process, the course coordinators were found to be the key persons involved. The data also revealed that there were conflicting priorities, as priorities between the lecturer/course writers and course coordinators seem to differ, a factor that affected their working relationship in terms of course module development. While the lecturer/course writers complained about their heavy workload and having to juggle their teaching duties and work for the in-service program, the course coordinators wanted modules written on-time to meet established deadlines. Two course coordinators clearly expressed this tension as follows:

We are challenged by the people with whom we work who have other commitments, especially the course writers who also have to teach, and sometimes they fail to meet the deadline we give them and this bring much pressure on us that results in a delay to deliver a module in the due time... . working with them is not easy because so many times they complain that they are overworking, overloaded with teaching hours. In most cases, they give priority to pre-service work, the traditional mode.

Some times some lecturers say they are overloaded, and if you do not keep going to remind them you will not get the work done. And the deadline arrives, yet you do not have the material. So we have to make sure that each lecturer is writing for us. We have to go in their department and some times phone them and keep checking on them.

\section{The lecturer/course writer and course tutor relationship: Challenges in student support}

Another important feature of the DL program of teacher tertiary education in Rwanda is student support. The high importance placed on student support is manifest in one of the three operational departments of the distance training office. Student academic support, therefore, was designed as part of the program structure as narrated in the following:

To support students, they come each weekend to the 10 training centers set up for that purpose throughout the country. They meet with the course tutors, who help 
them as needed. If need be, the students may come and do their practical lab here in the Institution, but otherwise they have small labs in the centers.

This quote seems to imply a close collaboration between the lecturers/course writers and the course tutors (facilitators), but unfortunately this was not the case. The data collected showed a breakdown in communication between the lecturers/course writers who see themselves as belonging mainly to the Institution and the tutors who report to the distance training office. The lecturers/course writers complained about not having control over what is happening in the field, especially in terms of the tutors' work and students' assignments. Tutors, on the other hand, complain about not having any opportunity to meet with lecturer/course writers to discuss the course materials and students' progress when necessary. One lecturer/course writer expressed his side of the problem as follows:

There is no relationship between distance training office and us, the course writers. There has not been that integration. They are doing things on their own and we are doing ours. There is a movement towards integration, but not yet done. So those tutors deal with the distance training office and do not have any relationship with the department and faculties. So our working relationship with the distance training office is to write the module, to go out for face-to-face sessions, give and mark the exam. The tutors there, they mark the assignments and facilitate students, but we do not have any contact with them. And this is a problem. We write the module and someone else facilitates and marks the assignment. We see the students only during the face-to-face sessions. This is why we are saying the distance training office should be integrated into the Kigali Institute of Education structure, so that all of them should be answerable to the departments and to the deans. Like now, we do not know where the marks of the assignments of our students are. They are some where in the field!

Tutors also faced significant challenges as well, which is clearly articulated in the following:

But we do not participate in module elaboration. We receive the module with students when they are already elaborated. Sometimes but rare, they organize a meeting between us and course writer at the Kigali Institute of Education just to discuss the elaborated module. We would wish to participate in the writing of the module. But we do understand the module because we facilitate those in our area and most of them are the subject we have gone through. When we have any comment on a module, we do a written report and send to the Distance Training Office to handle it. Some times, especially in sciences, the level of the module is higher than the students and we, as subject tutors, we spend a lot of time with students explaining so that they can understand. There is almost no collaboration between us and course writers, except some individual initiatives from tutors. Like for the assignment, because we are the one to mark them, we just mark each one the way we understand following the marking scheme given along with the module. And we do not have any exchange on the result of students with the course writers. We mark and send to them the results. But then they are the one to set and mark the exam. We would have appreciated to have more collaboration with the course writers, which makes our work easier and benefit the students. Anyway, we have a feeling that the tutors are not really taken into consideration, and some of us are no longer motivated and have given up. 


\section{Discussion and Conclusion}

To run a successful DL program, a wide variety of skills are required. Some of the requisite skills, however, are not commonly found in tertiary institutions. Thus other people such as media producers, broadcasters, print shop managers, warehouse supervisors, experimental kit assemblers, and postal system experts are required (Dharanajan, 1996). Further, a pool of tutors to support distance learners is necessary. Managerial staff consisting of a centre manager, student counsellors and/ or learner support, and other administrative staff at each study centre are similarly required. Based on his experience with open universities, Dharanajan (1996) asserted that in most DL programs, more full-time administrative staff are required than full-time academics, and numerous seasonal and part-time staff who are also needed. In this study, all lecturer/course writers are drawn from full-time faculty in the pre-service program; as such, they are only employed part-time in the DL program. All tutors are employed part-time. This large pool of part-time labour can be compared to that of the administrative arm of the DL program, which is carried out within the departments of the DL units by full-time staff members consisting of a program director, department heads, and course coordinators.

According to the data, all staff in the DL program came from the traditional education system, and most had little or no experience in distance education settings prior to joining the Institute's DL program. The problem, however, is because an unusually wide variety of skills are required both on the part of academic and non-academic staff, the competencies required to organize and run a DL program are not typically available. Thus investments in people to become confident distance educators, to work in teams, to share a common vision and bring commitment to the program, are seen as a much more important investments in a DL system, than investments in material infrastructures (Dhanarajan, 1996; Kinyanjui, 1998). Capacity building and staff development through intensive and progressive training and support was one of the Institute's DL tertiary teacher education program strengths, an assertion that is supported by the results of this study. Although capacity building and staff development are important to all aspects of the Institute's DL program, it becomes even more important in course materials development because, in most cases, DL course materials are developed by lecturers from on-campus programs. As Perraton and Creed (1999) point out, typically academic lecturers do not have any experience in DL materials writing. As such, those academics charged with writing course materials underwent intensive training to equip them with the necessary skills for writing DL materials. The end result is that in-house produced modules are now user friendly, having been improved over time with each iteration. Other staff members underwent similar training in areas such as student support, DL program management, module editing, and course materials production.

Several studies (Dillon and Stephen, 1992; Rockwell, Furgason and Marx, 2000) have been conducted in the area of faculty reward and incentive. These studies show that rewards and incentives are important components of distance education programs in dual mode institutions, particularly since most of these academics are well established in the conventional mode and are typically resistant to change. In this study, it was found that rewards in the form of extra remuneration was used to motive faculty and compensate them for their heavier workload. Such rewards resulted in greater degree of observable commitment by faculty members in the Kigali Institute's DL program. The effort used by the Kigali Institute are in line with those proposed by Rockwell and colleagues (2000) who concluded that incentives should be provided for faculty to participate in distance education. Institutional rewards, workload expectations, and incentives are all crucial in getting faculty members to commit themselves to distance learning. In the same study, however, Rockwell and colleagues also found that faculty interest in distance education may also be intrinsic. Faculty are also interested in innovative instruction and applying new teaching techniques. The results of the study reported here echoes the findings made by Rockwell et al. (2000), indicating that while monetary reward is vital, DL lecturers/course writers also 
reported their interest in learning new things, primarily through the exchange with the University of London. Thus the motivation of lecturers/course writers to join and participate in the Kigali Institute's DL program was based on much more than monetary reward -- it was also based on the opportunity to learn and do something new.

The results of this study revealed that the working relationship between lecturer/course writers and course coordinators was difficult at best. While the course coordinators' major concern was to meet the deadline and get the DL module written within a pre-planned timeframe, the lecturer/ course writers' first priority was their teaching responsibility at the residential program. This finding echoes that of Kamau (1999) who reported on the experiences of the distance education unit at the University of Botswana. Citing workloads from their parent departments as a major constraint, Kamau found that task completion had been a nightmare among module writers who failed to meet the agreed deadlines. As a consequence, there was a delay in the course implementation schedule (Kamau, 1999). Perraton and Creed (1999) echoed the findings by Kamau when they reported that the dual-responsibility of faculty members in African dual-mode institutions typically made it difficult to find time for writing course materials for DL programs. For faculty members to be efficient in their dual roles, their workload must therefore be realistically considered.

The findings also revealed a breakdown in communication between lecturer/course writers and course tutors. Generally, the working relationship between lecturer/course writers and course tutors was not described in positive terms. According to Perraton and Creed (1999) in dual-mode institutions it is common practice that the faculty members who teach a particular subject on campus, write the course materials for the DL program on that subject. Course tutors, on the other hand, simply facilitate the learning process. Nonetheless, it is the course tutors who are often the closest and only link to students in distance learning settings. Thus the working relationship between the lecturer/course writer and tutor is critical. Without clear communication, course tutors often cannot effectively facilitate the DL modules. Failure to enhance this relationship may also reduce tutors' motivation, particularly if they are employed part-time and have other competing professional and social obligations. A consequence, student performance may be

negatively affected. Strategies to enhance effective communication between lecturers/ course writers and tutors must therefore be put in place.

\section{Acknowledgement}

I thank all those who willingly participated in this study. I also thank the contribution of the supervisor of this project, Professor N.S. Gwele, along with the Government of Rwanda for granting the much needed funding to carry out this study.

\section{References}

Anderson, S. K., and Middleton, V. (2002). You want me to do what? The cultural and psychological struggle of putting a course online. The Technology Source. Retrieved August 14, 2003 from: http://ts.mivu.org/default.asp?show=issue\&id=85

Clarke, M., Butler, C., Schmidt-Hansen, P., and Somerville, M. (2004). Quality Assurance for Distance Learning: A case study at Brunel University. British Journal of Educational Technology 35(1), 5-11. 


(1)

Dhanarajan, G. (1996). Setting Up Open Universities. Paper presented at British Council seminar: Quality Assurance in Open Learning in Higher Education. Bedford, United Kingdom, 2126 April, 1996. Retrieved October 16, 2004 from: http://col.org/speeches/MINEDAF 02.htm

Dillon, C. L., and Stephen M. W. (1992). Faculty: The neglected resource in distance education. American Journal of Distance Education 6(3), 5-18.

Garrison, R. (2000). Theoretical challenges for distance education in the 21st century: a shift from structural to transactional issues. International Review of Research in Open and Distance Learning 1(1). Retrieved September 25, 2006 from: http://www.irrodl.org/index.php/irrodl/article/view/2/333

Kamau, J. W. (1999). Challenges of course development and implementation in a dual mode institution. A paper presented as a case study at the Pan Commonwealth Form on open learning, University of Brunei, Darussalam Brunei. March, 1-5.

Kinyanjui, P. E. (1998). Distance and Open Learning in Africa: What works or does not work. A paper presented at the EDI/World Bank workshop on Teacher Education through distance learning. Addis Ababa, Ethiopia. Retrieved September 25, 2006 from: http://www.col.org/colweb/site/pid/3689

Levy, S. (2003). Six factor to consider when planning online distance learning program in higher education. Online Journal of Distance Learning Administration 6(1). Retrieved September, 252006 from: http://www.southwesterncc.edu/distlearn/tutorials/articles/Six\%20Factors\%20to\%20Cons ider.htm

Qualitative Solutions and Research (QSR) International (2002). NVivo 2. Retrieved August 30, 2006 from: http://www.qsrinternational.com/aboutus/company/company history.htm

Perraton, H., and Creed, C. (1999). Distance Education Practice: Training and rewarding authors. Cambridge, UK.: Institute of Community Studies, International Research Foundation for Open Learning.

Rwanda Ministry of Education (1999). A survey on the secondary school teachers'profile. Kigali: Ministry of Education, Science, Technology and Scientific Research.

Rockwell, K., Furgason, J., and Marx, D. B. (2000). Research and evaluation needs for distance education: A Delphi study. Online Journal of Distance Learning Administration 3(3). Retrieved September 25, 2006 from: http://www.southwesterncc.edu/distlearn/tutorials/articles/Six\%20Factors\%20to\%20Cons ider.htm

Rockwell, K., Schuaer, J., Fritz, S. M., and Marx, D. B. (1999). Incentives and obstacles influencing Higher Education faculty and administrator to teach via distance. Online Journal of Distance Learning Administration 3(3). Retrieved September 26, 2006 from: http://www.westga.edu/ distance/rockwell24.html .

Williams, P. E. (2003). Roles and competencies for distance education programs in higher education institutions. American Journals of Distance Education 17(1), 45-57. 
Yin, R. K., (2003). Case Study Research: Design and methods. London: Sage Publications.

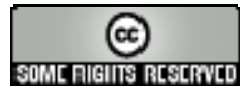

Athabasca

University 